\title{
Die toepassing van wasige logika in industriële beheerstelsels
}

\author{
I.S. Shaw
}

Navorsingsgroep vir Industriële Elektroniese Tegnologie, Fakulteit Ingenieurswese, Randse Afrikaanse Universiteit, Posbus 524, Auckland Park, 2006

Ontvang I September 1994; aanvaar 4 April 1995

\section{UITTREKSEL}

Die teorie van wasige versamelings is' $n$ metodologie vir die hantering van kwalitatiewe, nie-eksakte, onakkurate inligting op 'n sistematiese en rigoristiese wyse. Konvensionele beheertegniese benaderings verg 'n wiskundige model van die proses of stelsel onder beheer. Ingeval' $n$ presiese kennis van die prosesdinamika nie beskikbaar is nie, of die proses baie kompleks, nieliniêr, of bykans onbekend is, lewer konvensionele tegnieke geen bevredigende resultate nie en moet menslike beheeroperateurs nog steeds gebruik word. In teenstelling neem wasige logika die opgesomde empiriese kundigheid van menslike operateurs wat in kwalitatiewe, onakkurate wyse uitgedruk is en gebruik dit. Dus verteenwoordig wasige logika 'n praktiese benadering tot realistiese en komplekse industriële beheerprobleme, soos bewys deur sy wydverspreide sukses. Die algemene eienskappe van wasige beheerders is bewys deur middel van 'n eksperimentele opstelling, waardeur ' $n$ waardevolle insig verkry is in die ontwerpmetodiek en sy beperkings.

Gedurende byna sewe jaar van navorsingsaktiwiteite met betrekking tot wasige logika aan die RAU, is daar'n poging aangewend om ' $n$ Afrikaanse terminologie in hierdie belangrike gebied van moderne intelligente beheerteorie te vestig. In hierdie artikel word dié terminologie gebruik vir kommentaar deur die lesers.

\section{Abstract}

\section{The implementation of fuzzy logic in industrial controllers}

The theory of fuzzy sets is a methodology for the handling of qualitive, inexact, imprecise information in a systematic and rigorous way. Conventional control approaches require a mathematical model of the process or system to be controlled. However, when an accurate knowledge of the process dynamics is not available, or the process is highly complex or nonlinear, conventional techniques do not give satisfactory results and human control operators must still be used. In contrast, fuzzy logic captures and utilizes the accumulated empirical know-how of human operators expressed in qualitative, inexact, imprecise ways. Thus fuzzy logic represents a practical approach to realistic complex industrial control problems, as manifested by its widespread success. The general properties of fuzzy controllers have been verified by means of an experimental setup, whereby a valuable insight has been gained on to the design process and its limitation.

During nearly seven years of research activities in fuzzy logic at $R A U$, an effort was also made to establish an Afrikaans terminology in this important field of modern intelligent control theory. This terminology is introduced to elicit criticism from the readers.

\section{INLEIDING}

'n Dinamiese proses word as gemodelleer en geidentifiseer beskou wanneer die model sy toekonıstige gedrag kan voorspel as 'n resultaat van 'n bekende stimulus. Nietemin is die praktiese realiteit kompleks en is dit redelik moeilik om ' $n$ model wat 'n fisiese verskynsel in 'n wiskundige formulering verteenwoordig, totaal te omvat. Bowendien, om sodanige formulerings buigsaam te hou, word dikwels sekere beperkende aannames, soos byvoorbeeld lineariteit vereis. Die gemeenskaplike eienskap van algemene beheerteoretiese metodes wat vir modellering gebruik word, is dat hulle geldige en akkurate kennis van die prosesse wat beheer moet word, aanneem. Indien 'n persoon egter nie die innerlike werkinge van 'n komplekse proses wat hy graag wil modelleer, verstaan nie, lewer tradisionele tegnieke selde bevredigende resultate. Soos stelsels meer kompleks raak, raak dit toenemend moeilik om wiskundige modelle wat sowel betekenisvol as noukeurig is, oor hulle te maak. 'n Mens word dus genoodsaak om toe te gee dat onakkuraatheid en nie-eksaktheid in enige werklike stelseltoepassing aanvaar moet word. ${ }^{1}$

Die teorie van wasige versamelings is 'n metodologie vir die hantering van kwalitatiewe, nie-eksakte, onakkurate inligting op 'n sistematiese en rigoristiese wyse. Hierdie benadering voorsien 'n uitstekende werktuig vir die modellering van mensgeoriënteerde stelsels, ${ }^{2,3}$ veral omdat wasigheid ' $n$ belangrike faset van die menslike denkproses blyk te wees. In plaas daarvan om 'n presies gedefineerde of afgemete waarde van 'n veranderlike te gebruik, neig 'n mens om beskikbare inligting op te som deur dit in vae en onakkurate kategorieë, soos byvoorbeeld laag, medium en hoog te klassifiseer. Op hierdie wyse word die inligting wat van die buitewêreld ontvang word, gereduseer tot presies dit wat nodig is om die taak op hande met die verlangde noukeurigheid uit te voer. Dus is daar geen behoefte vir 
noukeurige wiskundige modelle nie, en op hierdie wyse het die menslike (d.w.s. wasige) besluitnemingsmeganisme aansienlik minder berekeningsbokoste en is dit dus vinniger en meer bevorderlik vir biologiese oorlewing as 'n ekwivalente noukeurige wiskundige model. Terselfdertyd is analisehulpmiddels nodig om ons in staat te stel om die struktuur van die beheerder te verstaan. Alhoewel die beheeringenieur die waarde daarvan mag insien om vae konsepte op 'n sistematisese wyse uit te druk, moet hy ook voorsien word van die analitiese insig om 'n ontwerpmetodiek te ontwikkel, veral met betrekking tot beheerprobleme wat nie analities opgeklaar kan word nie en wat vatbaar sou wees vir die gebruik van die wasige model. Te danke aan die feit dat wasige beheer die noodsaaklikheid van 'n presiese wiskundige model van die stelsel wat beheer moet word, elimineer, is "wiskundige modelvrye beheer" nou moontlik met die vermoë om komplekse nieliniêre stelsels wat voorheen onbeheerbaar was, outomaties te beheer. Hierdie beheeraksies kan nou beskryf word deur middel van linguistiese (taalkundige of verbale, in stede van numeriese) inset-uitset-verbande, wat dit moontlik maak om 'n beheerder daar te stel bloot op grond van 'n onderhoud wat met 'n ervare operateur gevoer is. Op hierdie basis word reëlgebaseerde wasige beheerders ontwerp. Aan die ander kant, deur gebruik te maak van relasionele wasige modelle ${ }^{5}$ en die daarop gebaseerde selflerende wasige beheerders, ${ }^{6.7}$ kan weggedoen word met die opstel van reëls. 'n "Model" van die stelsel wat deur 'n mens beheer word, word deur die selflerende wasige stelsel opgebou op grond van insetuitset-metings. Hierdie "Model" is 'n wasige afbeelding van die menslike beheeraksies en beheerstrategie en kan nou gebruik word om die beheerderuitset vir onbekende insette te genereer. Hierdie artikel sal egter beperk word tot reëlgebaseerde beheerders wat tans in die industrie die gewildste is.

Die afgelope tyd is die konstruksie en gebruik van wasige modelle vir industriële beheerstelsels, gebaseer op die teorie van wasige versamelings, aanvaar as 'n goed bruikbare metode in die geval van dinamiese stelsels waarvan die basiese dinamika of onbekend of te kompleks is vir konvensionele wiskundige metodes.

Die ontwerpmetodiek van reëlgebaseerde wasige beheerders is suksesvol gebruik in die ontwerp van 'n wye reeks van wasige beheerders, soos byvoorbeeld: 'n treinbeheerstelsel, ${ }^{19}$ outomobielstelsels, ${ }^{10}$ lugreëling, ${ }^{11}$ temperatuurbeheer, ${ }^{12}$ verskeie huishoudelike apparate soos wasmasjiene, ryskokers en stofsuiers, ${ }^{13}$ elektriese gelykstroom- en induksiemotoraandrywings, ${ }^{14.15}$ oliedistilleerders, ${ }^{16}$ outonome mobiele robots, ${ }^{10.17}$ 'n smeltoond, ${ }^{18}$ termiese stelselbestuur, ${ }^{19}$ sementoonde, ${ }^{20}$ rioolwateraanleg, ${ }^{21}$ polimerisasiereaktor ${ }^{22}$, verkeerskruising, $^{23}$ vullisverbrander ${ }^{24}$ en kraanwerk. ${ }^{25}$

\section{2. 'n KORT TEORETIESE OORSIG}

Die versamelings wat hieronder bespreek word, bestaan uit 'n eindige aantal diskrete elemente. Die rede is dat versamelingsteorie in die gebied van beheeringenieurswese deur middel van syferrekenaars geimplementeer word, wat eindigheid asook diskrete datamonsters vereis.

Gestel $U$ is 'n versameling van elemente $u$, dan word $U$ die gebied van belang en $u$ sy generiese elemente genoem. Gestel 'n diskrete eindige deelversameling $E$ van die gebied van belang $U$ wat die elemente $x_{0}, \ldots, x_{i}, \ldots, x_{n}$ bevat: $\mathrm{x}_{1} \in E$ Dan $E=\left\{\mu_{0} x_{0}, \ldots, \mu_{i} x_{i}, \ldots, \mu_{n} x_{n}\right\}$, waar $\mu$ die lidmaatskapwaarde is. In klassieke versamelingsteorie $x_{i} \in$ $E$ indien $\mu_{x_{i}} \in 1$, dit wil sê, $x_{t}$ is 'n lid of versameling $E$, terwyl $x_{i} \notin E$ indien $\mu_{x}=0$, d.w.s. $x_{i}$ nie ' $n$ lid of $E$ is nie. Gewone versamelingsteorie laat slegs volle lidmaatskap van 'n element toe.

\section{DEFINISIE 1: WASIGE VERSAMELING}

'n Wasige versameling $E$ in 'n gebied van belang $U$ word gekenmerk deur'n lidmaatskapfunksie waarvan die waardes in die interval $[0,1]$ lê, dit wil sê, $\mu_{E}: \rightarrow[0,1]$.

'n Wasige versameling kan beskou word as 'n veralgemening van 'n gewone versameling waarvan die lidmaatskapsfunksie slegs twee waardes $(0,1)$ kan aaneem. 'n Wasige versameling $E$ in $U$ kan dus verteenwoordig word deur 'n versameling van geordende pare van elemente $u$ en sy lidmaatskapswaarde: $\mathrm{E}=\left\{\left[u, \mu_{E}(u)\right] \mid u \in U\right\}$.

Gestel die veranderlike $u$ beteken spoed en motors waarvan die spoed $u=60 \mathrm{~km} / \mathrm{h}$ oorskry, behoort aan die versameling $E$, terwyl motors waarvan die spoed onder 60 $\mathrm{km} / \mathrm{h}$ bly, nie aan $E$ behoort nie. Die skielike sprong vanaf nie-lidmaatskap na volle lidmaatskap is egter onrealisties en uit die wet se oogpunt sterk gesproke onafdwingbaar. Byvoorbeeld, moet die spoed $u=60,02 \mathrm{~km} / \mathrm{h}$ as 'n wetsoortreding beskou word? Daar blyk 'n sekere wanaanpassing te bestaan tussen die abstrakte wiskundige wêreld en die werklike wêreld! In die fisiese wêreld is die grense van versamelings nie skerp nie, dus kan die lidmaatskap of nie-lidmaatskap van 'n spesifieke element op basis van klassieke versamelingsteorie nie met sekerheid bepaal word nie.

Wasige versamelingsteorie word gebaseer op hierdie feit. ' $n$ Wasige versameling is ' $n$ onpresies-gedefinieerde bondel van elemente waar die oorgang vanaf nie-lidmaatskap na volle lidmaatskap eerder geleidelik as skielik is. Dit wil sê, die bogenoemde spoed van $60,02 \mathrm{~km} / \mathrm{h}$ mag wel aan die versameling van wetsoortreders behoort, maar slegs tot 'n mate van 0,2 of 20 persent! 'n Mens mag sê dat hierdie motor " "n bietjie vinniger" as die toegelate spoed ry. Hierdie " "n bietjie vinniger" is 'n onpresiese, linguistiese (taalkundige), wasige uitdrukking en die versameling $E$ is 'n wasige versameling en nie meer 'n skerp een nie. Dus in stede van twee waardes: waar $(\mu=I)$ en nie-waar $(\mu=0)$, word enige lidmaatskapwaarde in die interval $[0,1 /$ toegelaat en gebruik as 'n "tot-'n-sekere-mate-ware"-waarde. Hierdie stelling "tot 'n sekere mate waar" is 'n linguistiese, dit wil sê, nienumeriese definisie.

Gestel die diskrete wasige versameling $F$ bestaan uit ses elemente:

$F=\left\{x_{1}, x_{2}, x_{3}, x_{4}, x_{5}, x_{6}\right\}$, en 'n deelversameling $X=\left\{x_{3}\right.$, $\left.x_{4}, x_{5}\right\}$.

Die lidmaatskapfunksie (wat uit die individuele lidmaatskapwaardes bestaan) van deelversameling $X$ met betrekking tot elke element van $F$ is byvoorbeeld:

$\left(x_{1}\right)=0 ;\left(x_{2}\right)=0.35 ;\left(x_{3}\right)=0.9 ;\left(x_{4}\right)=1 ;\left(x_{6}\right)=0.2$. 
Deelversameling $X$ met betrekking tot $F$ kan ook in die volgende manier geskryf word:

$X=\{0,0.35,0.9,1,1,0.2\}$ waar die elementsimbole ter wille van duidelikheid weggelaat is.

Die versameling van lidmaatskapwaardes vir elke element is die lidmaatskapfunksie of lidmaatskapvektor: $X=\left\{\mu_{1} \mu_{2} \mu_{3} \ldots \mu_{n}\right\}$. 'n Wasige versameling word dus volkome gedefinieer deur die lidmaatskapwaardes van sy elemente.

In die voorafgaande gevalle was

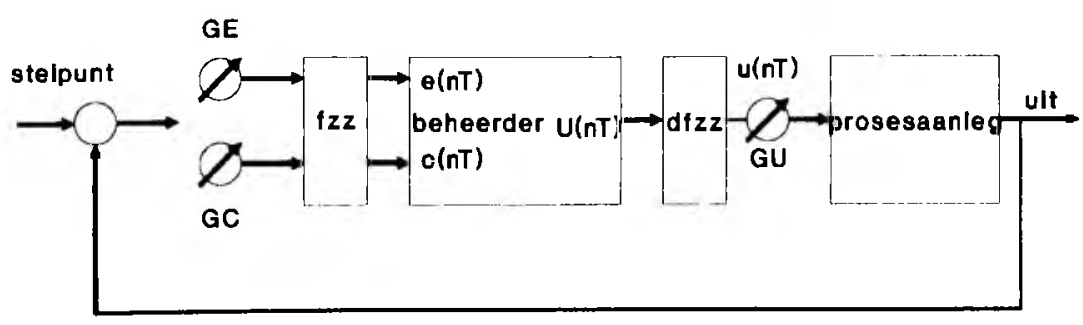

FIGUUR I: Basiese wasige beheerlus. FZZ: verwasiger; DFZZ: ontwasiger.

versameling $F$ eindig, met ander woorde, dit bevat 'n diskrete aantal elemente. Die totale bestek van elemente word die gebied van belang genoem. Byvoorbeeld, beskou $K$ diskrete insette $\boldsymbol{u}(k)$ van 'n stelsel wat lede van 'n insetversameling $U=\{u(k)\}$ is. ( $u$ is dus die gebied van belang vir die inset, met ander woorde $U$ bevat alle moontlike waardes van $u(k)$ wat kan voorkom).

\section{DEFINISIE 2: STEUNSEL, OORSTAPPUNT, WASIGE ENKELTJIE}

Die steunsel van 'n wasige versameling $E$ is 'n gewone versameling van alle punte $u$ in $U$ waar $\mu_{E}(u)>0$. Die element $u$ in $U$ waar $\mu_{E}=0.5$ is die oorstappunt. Die wasige versameling waarvan die steunsel 'n enkele punt in $U$ met $\mu_{E}=1.0$ is, is ' $n$ wasige enkeltjie.

Gestel: $U=\left\{u_{1}, u_{2}, \ldots, u_{i}, \ldots, u_{n}\right\} ; A=\left\{\mu_{\mathrm{A}}\left(u_{i}\right), u_{i}\right\}$; $B=\left\{\mu_{B}\left(u_{i}\right), u_{i}\right\} ; \mu_{i}\left(u_{i}\right)=[0,1] ; A \subset U, B \subset U ;$

Wasige versamelings, soos gewone versamelings, kan met mekaar gekombineer word deur middel van die versamelingteoretiese operasies snyding, vereniging en komplementering, wat deur hul lidmaatskapwaardes gedefinieer word.

\section{DEFINISIE 3: SNYDING}

Die snyding van $A$ en $B$ is die grootste wasige versameling wat in beide wasige versamelings $A$ en $B$ bevat is. Die snyding van twee wasige versamelings $A$ en $B$ met hul ooreenkomstige lidmaatskapfunksie $\mu_{A}$ en $\mu_{B}$ is 'n wasige versameling $C=A \cap B$, waarvan die lidmaatskapfunksie $\mu_{A \cap B}$ as gevolg bepaal word:

$\mu_{A \cap B}(u)=\operatorname{MIN}\left[\mu_{A}(u), \mu_{B}(u)\right], u \in U$

Die snyding kom ooreen met die logiese en $E N$ operator.

\section{DEFINISIE 4: VERENIGING}

Die vereniging van wasige versamelings $A$ en $B$ met hul ooreenkomstige lidmaatskapfunksie $\mu_{A}$ en $\mu_{B}$ is 'n wasige versameling $C=A \cup B$, die kleinste wasige versameling wat $A$ en $B$ beide bevat. Die lidmaatskapfunksie hiervan word as volg bepaal:

$$
\mu_{A \cup B}(u)=\operatorname{MAX}\left[\mu_{A}(u), \mu_{B}(u)\right], u \in U
$$

Die vereniging stem ooreen met die logiese $O F$ operator.

\section{DEFINISIE 5: KOMPLEMENT}

Die komplement van 'n wasige versameling is $A$ ' en word gedefineer deur sy lidmaatskapfunksie

$\mu_{A},(u)=\left[1-\mu_{A}(u)\right], u \in U$

Die komplement stem ooreen met die logiese $N I E$ operator.

\section{WASIGE BEHEERDERS}

Die konsepte van wasige versamelingsteorie is gevestig deur Zadeh ${ }^{1}$ vir dinamiese stelsels wat te kompleks of swak gedefinieer is en dus nie geskik vir konvensionele wiskundige modelleringstegnieke is nie. Mamdani ${ }^{26}$ en Larsen $^{27}$ het wasige versamelingsteorie in wasige beheerders (WB) toegepas. Sedert dien het etlike navorsers WB's vir verskeie toepassings ontwikkel. ${ }^{28}$ In die algemeen bestaan WB's uit ' $n$ stel linguistiese vorwaardelike stellings wat van die kennis van ervare menslike operateurs ten opsigte van die aanleg onder beheer afgelei is. Hierdie stellings definieer' $n$ beheerprotokol wat beheertoestande met beheeraksies verbind deur middel van "Indien...dan"-reëls. Die WB kan beskou word as 'n wasige redeneringsproses wat menslike kundigheid gebruik in die emulering van menslike beheerstrategieë. Dit word uitgevoer in die vorm van kwalitatiewe inligting oor die aanleg of proses onder beheer en die inligting word in terme van "Indien...dan"-reëls uitgedruk. Byvoorbeeld, in die geslotelusstelsel van figuur 1 verbind ' $n$ tipiese beheerreël die prosesfout $e$ en die fouttempo $c$ met die verandering in die prosesinset $u$ wat toegepas moet word om die stelsel se werkverrigting te verbeter. 'n Substel van die beheerreëls word in 'n kwalitatiewe manier as volg beskryf:

Reël 1. Indien fout $e=G R O O T$ en fouttempo $c=N U L$, dan prosesinsetverandering $\Delta u=G E M I D D E L D$;

Reël 2. of indien fout $e=K L E I N$ en fouttempoc $=N U L$, dan prosesinsetverandering $\Delta u=K L E I N$; 
Reël 3. of indien.....

In hierdie struktuur is $e, c$ en $u$ linguistiese veranderlikes en hul waardes is wasige versamelings soos GROOT, KLEIN, $N U L$, ens. wat gekenmerk is deur $E_{i}, C_{i}, U_{i}$, oor die gebiede van belang $E, C, U$ respektiewelik. Hierdie $(E, C, U)$ is veronderstel as diskreet en eindig, sodat elke gebied van belang ' $n$ versameling van elemente is:

$E=\{e\}, C=\{c\}, U=\{u\}$

Let op dat wasige versamelings $E_{i}$ en $C_{i}$ deur middel van 'n $E N$ operator verbind is wat in versamelingsterme 'n snyding verteenwoordig. Op dieselfde manier beteken die $O F$ operator ' $n$ vereniging.

In elke beheerreël word aan die veranderlikes wasige waardes toegeken wat hul linguistiese belangrikheid verteenwoordig. Hierdie wasige waardes word uitgedruk as wasige deelversamelings van hul ooreenkomstige gebiede van belang. Dus kan ' $n$ beheerreël verkort word:

" INDIEN E = I, EN C = C DAN $\Delta u=U_{i} "$

Gestel die WB bestaan uit $N$ reëls, 'n substel waarvan uitgedruk kan word as:

$$
\bigcup_{n=I}^{N} I N D I E N e=E_{i} E N c=C_{i} D A N \Delta u=U_{i}
$$

Die wasige deelversamelings $E_{i}, C_{i}, U_{i}$ word gedefinieer deur' $n$ versameling van geordende pare:

$E_{i}=\left\{\left(e, \mu_{E_{i}}(e)\right\} \in E ; C_{i}=\left\{\left(c, \mu_{c_{i}}(c)\right\} \in C ; U_{i}=\left\{\left(\Delta u_{1} \mu_{U_{i}}(\Delta u)\right\} \in U\right.\right.\right.$

waar $e, c$ en $u$ elemente van die diskrete gebiede van belang

is en $\mu_{E_{i}}(e), \mu_{c_{i}}(c)$ en $\mu_{U_{i}}(\Delta u)$

is die ooreenkomstige lidmaatskapwaardes wat die mate van die element se deelname as 'n lid van die deelversameling aandui. Dus kan 'n gekoppelde $i$ de reël beskryf word deur 'n wasige relasiematriks $R_{i}$ oor 'n gebied van belang $E x C x U$ (waar $x$ die Kartesiese produk beteken) en sy lidmaatskapfunksie uitgedruk word as

$\mu_{R_{i}}(e, c, \Delta u)=f_{\rightarrow}\left(\mu_{E_{i}}(e), \mu_{C_{i}}(c), \mu_{U_{i}}(\Delta u)\right)$

waar $f_{\rightarrow}(., .,$.$) 'n algemene vorm van die$ implikasiefunksies is ene $E, c \in C, \Delta u \in U$ is. Die implikasiefunksie $f_{\rightarrow}(., .,$.$) kan beskryf word deur t$ norme. ${ }^{5}$ Die keuse van 'n implikasiefunksie word of op voorkeur of op die konteks van 'n gegewe taak gebaseer. In die algemeen word alle beheerreëls deur 'n enkele wasige relasiematriks $R$ saamgestel. Die fout en fouttempo word verkry vanuit die werklike proses en word geskaleer deur die konstante $G E$ en $G C$ voor kwantifisering tot die naaste element van die gebied van belang. Die proses van omsetting van niewasige na wasige waardes word verwasiging genoem. Indien hierdie wasige deelversamelings van fout $(e)$ en fouttempo $(c)$ deur
$E^{\prime}$ en $C^{\prime}$ respektiewelik verteenwoordig word, word prosesinset $U^{\prime}$ gegee as

$U^{\prime}=E_{0}^{\prime} C_{0} R$

waar $o$ die wasige saamsteloperator is. ${ }^{2}$ Die resultaat is dus 'n wasige versameling en in die werklikheid word daar 'n deterministiese beheerbesluit vereis. 'n Moontlike oplossing is om die sentroïed van die elemente van die wasige versameling $U^{f}$ te kies. ${ }^{7}$ Die resultaat word dan vermenigvuldig deur die skaalfaktor $G U$ om die niewasige prosesinset-verandering te bepaal. Hierdie proses wat 'n niewasige uitset vanuit ' $n$ wasige genereer, wordontwasiging genoem. Die drie skaalfaktore $G E, G C$ en $G U$ word deur die gebruiker gekies; hulle is soortgelyk aan die winsverstellers van proporsionele-integrale-differensiële (PID) beheerders. Die faktore $G E$ en $G C$ het 'n wesenlike invloed op die werkverrigtingsfaktor asook die beheeraksie terwyl die parameter $G U$ slegs die uitset raak. ${ }^{26}$

\section{EKSPERIMENTELE VOORBEELD}

Daar word verwag dat die voordele van wasige beheer (dit wil sê, die beheer van komplekse, nieliniêre of swak bekende stelsels) hoofsaaklik in industriële prosesbeheerstelsels optimaal benut sal kan word. Nietemin word hier die klassieke beheerprobleem van 'n omgekeerde pendulum as 'n eksperimentele voorbeeld vir die aanwending van wasige logika in beheerstelsels gekies. Die rede daarvoor is dat wasige beheerders ' $n$ eienaardige ontwerpsmetodiek verg en die doel van hierdie artikel is om dit deur middel van 'n betreklik eenvoudige aanleg te illustreer, sonder om die belangrike kenmerke van die proses te ignoreer.

Verwys na figuur 2. Die pendulum word beperk om in net een vlak te beweeg. Die probleem is nou om die pendulum, wat inherent sal neig om om te val, regop te hou. Dit word gedoen deur die hoekuitwyking $\theta$ so na as moontlik aan nul te hou. Dit is duidelik dat die stelsel inherent onstabiel is. Die pendulum sal slegs regop bly staan

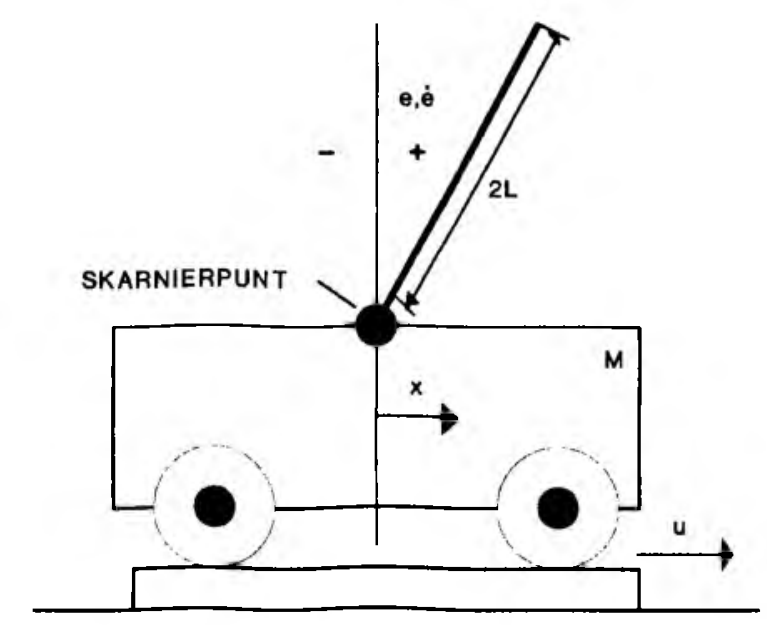

FIGUUR 2: Omgekeerde pendulum. 
indien die korrekte beheerkrag $u$ op die wiele van die karretjie uitgeoefen word.

Die tradisionele benadering tot die bepaling van die korrekte beheerkrag $u$ behels dat 'n akkurate wiskundige model van die totale stelsel opgestel moet word. Die opstel van die wiskundige model is baie tydsaam en gekompliseerd. Die stelsel se gedrag word deur die volgende stel differensiaalvergelykings beskryf ${ }^{29}$

$(I=m L)(\ddot{\theta}-m L(\mathrm{~g} \sin \theta-\ddot{x} \cos \theta)$

$u=(m=M) \ddot{x}+m L\left(\ddot{\theta} \cos \theta-\theta^{2} \sin \theta\right)$

waar $I=\frac{1}{3} m L^{2}=$ die traagheidsmoment van die pendulum om sy massamiddelpunt.

$m=$ massa van die pendulum.

$M=$ massa van die karretjie.

$x=$ verplasing van die karretjie.

$L=1 / 2$ van pendulumlengte.

Uit die bostaande is dit duidelik dat die dinamiese gedrag van die stelsel deur 'n stel nieliniêre tweede-ordedifferensiaalvergelykings beskryf word en dit is baie moeilik om 'n eksakte oplossing vir die vergelykings te bepaal. Om die nielineariteit te verwyder, word $\theta$ tot klein uitwyking beperk sodat die volgende vereenvoudigings geld:

$\sin \theta \approx \theta$ en $\cos \theta \approx l$ waar $\theta$

Die stelsel se vergelykings vereenvoudig dan na:

$\left(I+m L^{2}\right) \ddot{\theta} \approx m L(g \theta-\ddot{x})$

$u \approx \ddot{x}(m+M)+m L \theta$

Die oplossing van die gelineariseerde probleem behels dan die bepaling van 'n geskikte $u$ om die pendulum mee te balanseer. ${ }^{6}$

\section{WASIGE BEHEERDERONTWERPS- METODIEK}

By die benadering van die pendulumprobleem vanaf die wasige beheerdomein, is die opstel van 'n presiese wis-kundige model nie meer noodsaaklik nie. In der waarheid word geen wiskundige eienskappe, soos byvoorbeeld die massa van die karretjie of die pendulum, en die lengte van die pendulum benodig nie. (Hierdie onkunde moet egter later deur 'n breedvoerige instemmingsprosedure gekompenseer word.) Met die wasige beheerteorie-benadering word die linearisering ook nie vereis nie. Die gewenste beheeruitsette om die krag $u$ te paal, kan nou taalkundig neergelê word. Die beheeraksies word in die vorm van reëls neergelê wat die gewenste gedrag van die stelsel bevat. Hierdie reëls is gebaseer op die beheeraksies wat deur die mens uitgevoer sal word wanneer hy 'n omgekeerde pendulum op sy hand balanseer.

Die beheerstrategie wat vir die probleem voorgestel is, kan as volg opgesom word:

a) As die pendulum nie beweeg nie en vertikaal is, moet die karretjie nie beweeg nie.

b) Sou die pendulum na links of regs kantel, moet die karretjie sodanig versnel word dat dit die pendulum weer vertikaal laat staan:

Kantel die pendulum na regs moet die karretjie vinnig na regs versnel word om die kanteling teen te werk en omgekeerd.

c) By die beheer van die eksperimentele stelsel word daar ook aandag geskenk aan posisiebeheer van die karretjie. Aangesien die karretjie normaalweg in 'n beperkte ruimte bedryf gaan word, is dit nodig om te verseker dat die karretjie nie buite die gespesifiseerde area gaan nie. Die beheerstrategie is as volg: daar word aanvaar dat die karretjie vanaf die middel van die area sal begin loop. Sou die posisie van die karretjie sodanig verander dat dit neig om buite die gestelde grense te gaan, moet die karretjie sodanig versnel word dat dit na die beginposisie terugkeer. Sodra die beginposisie bereik is, word die normale beheeraksies dan weer voortgesit. Die wasige beheerder moet dus die uitvoer van bostaande aksies behartig.

Die basiese stelsel bestaan uit ' $n$ pendulum wat bo-op ' $n$ karretjie gemonteer is. Die karretjie en die pendulum se beweging word tot een vlak beperk. Die karretjie word aangedryf met behulp van 'n elektriese gelykstroommotor en 'n aandryfstelsel. Deur nou die stroomrigting en grootte van die motor reg te beheer, kan die gewenste uitsetkrag $u$ verkry word. Die beheer van die motorstroom geskied deur middel van 'n algoritme wat in 'n mikrobeheerder loop. Die algoritme is gebaseer op die wasige beheerteorie wat reeds bespreek is. Hierdie algoritme verseker die uitvoer van die gewenste beheeraksie om die pendulum vertikaal te hou. Die stelsel is tydgemonsterd met twee fisiese insette: die hoekverplasing $\theta$ van die pendulum en die verplasing $x$ van die karretjie. Die derde inset tot die beheerder is die

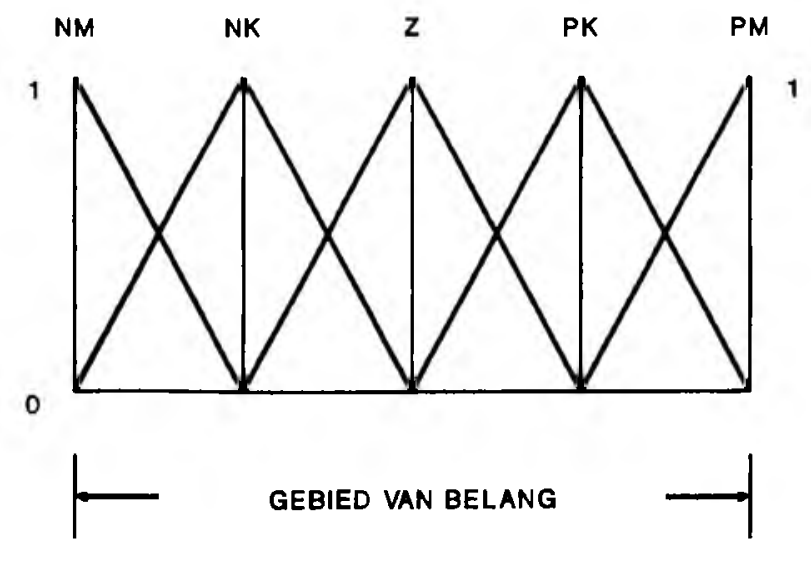

FIGUUR 3: Verwasigingsdriehoeke. 


TABEL 1 Oorspronklike wasige relasiematriks
\begin{tabular}{|c|c|c|c|c|c|}
\hline & NM & NK & Z & PK & PM \\
\hline N & & & NM & & \\
\hline NK & & & NK & Z & \\
\hline Z & NM & NK & Z & PK & PM \\
\hline PK & & Z & PK & & \\
\hline PM & & & PM & & \\
\hline
\end{tabular}

hoeksnelheid $\theta$ wat deur middel van differensiasie vanuit die hoekposisie $\theta$ bepaal word. Die uitset van die beheerder is in die vorm van ' $n$ beheersein wat gebruik word om die motorstroom en dus ook die versnelling van die karretjie te beheer.

Die ontwerp van 'n WB bestaan uit vier stappe: (i) verwasiging; (ii) opstelling van ' $n$ wasige reëlingstruktuur (dit wil sê die kundigheidsbasis); (iii) uitsetskatting; (iv) ontwasiging. Hierdie komponente is met mekaar verbind soos in figuur 1 .
Vyf wasige lidmaatskapfunksies (dit wil sê kwantifiseringsterme) is as volg gekies:

$N M=$ negatief medium; $N K=$ negatief klein; $P K=$ positief klein; $P M=$ postief medium; $Z=$ zero,nul.

Die rede vir net vyf funksies is dat die bestek van die veranderlikes nie so groot is dat die ekstra berekeningstyd wat gepaardgaan met meer gebiede geregverdig is nie. Die vorm van die verdeling van die gebied van belang is in die vorm van vyf simmetriese driehoeke wat mekaar oorvleuel (figuur 3). Hierdie is die aanvangsverdeling wat later aangepas moes word.

Die reëls vir die pendulum is afgelei deur die skatting van beheeraksies wat die mens sou uitvoer om die pendulum te beheer. Die reëls vir die pendulum is afgelei deur die skatting van beheeradvies wat die mens sou uitvoer om die pendulum te beheer. Die reëls bevat beide die insette $\theta$ en $\theta$ en beeld die insette af op 'n enkele uitset $I$. Die algemene vorm van die reëls is as volg:

INDIEN $\theta=$ (.) en $\theta=$ (.) DANI $=$ (.)

Die hakies dui op die wasige linguistiese lidmaatskapsterme waarin die gebiede van belang verdeel is. Vir die pendulum is daar oorspronklik 'n totaal van 11 reëls wat die beheer daarvan sal verseker, opgestel. Die reëlmatriks word in tabel 1 opgesom.

In tabel 1, op die horisontale as word die hoeksnelheid $\theta$ en op die vertikale as die hoeksnelheid $\theta$ aangedui. Die inskrywings in die tabel is die gewenste wasige uitsetstroom vir die beheer van die pendulum. So byvoorbeeld dui die

FIGUUR 4: Afleiding van die wasige uitset. 
inskrywing in die middel van die tabel die volgende reël aan:

Indien die hoekuitwyking nul is en die hoeksnelheid nul is dan moet die uitsetstroom nul wees.

Soortgelyk bepaal al die inskrywings in die tabel die gewenste gedrag van die karretjie om die pendulum te balanseer. Die reëls stem ooreen met die beheeraksies wat die mens sou uitvoer om die pendulum te balanseer.

Die wyse waarop 'n uitset geskat word, word nou kortliks bespreek. Veronderstel 'n pendulumhoek van $15^{\circ}$ en hoeksnelheid van $-10 \%$. Wat sal die geskatte stroom $I$ wees? Beskou byvoorbeeld hoe die insetpaar $(15,-10)$ die reël $(Z, Z ; Z)$ aktiveer. Verwys na figuur 4 .

Aanvaar die verdeling soos aangedui in figuur 3 . Die hoekwaarde van $15^{\circ}$ definieer dan 'n nul hoek tot die graad 0.2 . Die hoeksnelheid van $-10 \%$ definieer 'n nul hoeksnelheid tot 'n graad 0.5 . Dus:

$m_{z}^{\theta}(15)=0.2$ en $m_{z}^{\theta}(-10)=0.5$

Die wyse waarop die waardes nou gekombineer kan word is deur middel van die $M I N$-operator aangesien die twee reèls as $E N$ by mekaar aansluit. Die kleinste van die waardes word dus nou as die beslissende een geneem: die reël $(Z, Z ; Z)$ word dus tot 'n graad:

$\min \left[m_{z}{ }^{\theta}(15), m_{z}^{\theta}(-10)\right]-\min (0.2,0.5)=0.2$

geaktiveer. Die wasige versameling van nul uitsetstroom moet dus nou tot die graad 0.2 geaktiveer word. Hierdie aktivering word in figuur 4 as die gekleurde gebied getoon. Op 'n soortgelyke wyse word al $l l$ van die reëls in parallel geaktiveer. Die finale wasige uitsetstroom is dan nou die som van al $/ /$ reëls se bydrae tot die uitset. Die ontwasigde uitset is dan die sentroïed van die som van die verskeie gebiede wat geaktiveer is. Figuur 4 toon hoe die uitset vir slegs twee geaktiveerde reëls bepaal word.

Die empiriese instemming van 'n wasige beheerderontwerp is 'n baie belangrike proses. By die opstel van reëls is die meganiese eienskappe van die karretjie hoegenaamd nie in ag geneem nie. Die feit dat 'n wasige beheerder vir' $n$ meer of minder onbekende aanleg ontwerp kan word, moet betaal word deur 'n sikliese probeer-entref-instemmingsproses. Die opsies wat gewoonlik tot die ontwerper se beskikking is, behels die volgende:

- Die vorm van die lidmaatskapfunksies van die veranderlikes kan verander word.

- Die inskrywings in die relasiematriks kan gewysig word. Reëls kan dus bygevoeg of weggeneem word. Die eksperimentele stelsel is dus op die volgende manier gewysig. Die lidmaatskapfunksie van die hoekposisie is verander om 'n baie skerp nul driehoek rondom die gewenste vertikale posisie te vorm. Dit het die beheerder baie sensitiewer gemaak vir hoekuitwykings rondom die vertikale (nul) posisie. So ook is die definisie van die $P M$ - en die $N M$-driehoek nader na dieZ-verwysing gebring. Die respons van die stelsel was nou flinker. Die hoeksnelheid se lidmaatskapfunksie is ook 'n bietjie na die middel verskuif om die beheerder se sensitiwiteit vir beweging van die

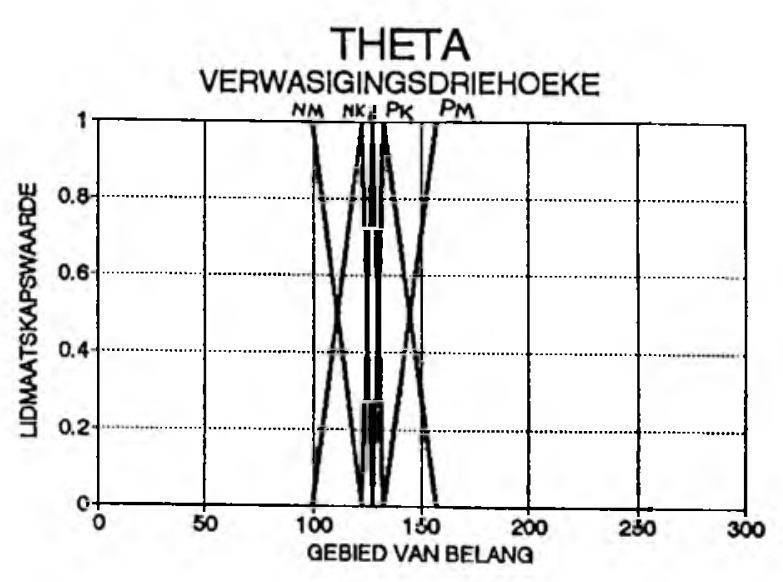

FIGUUR 5: Theta-verwasigingsdriehoeke.
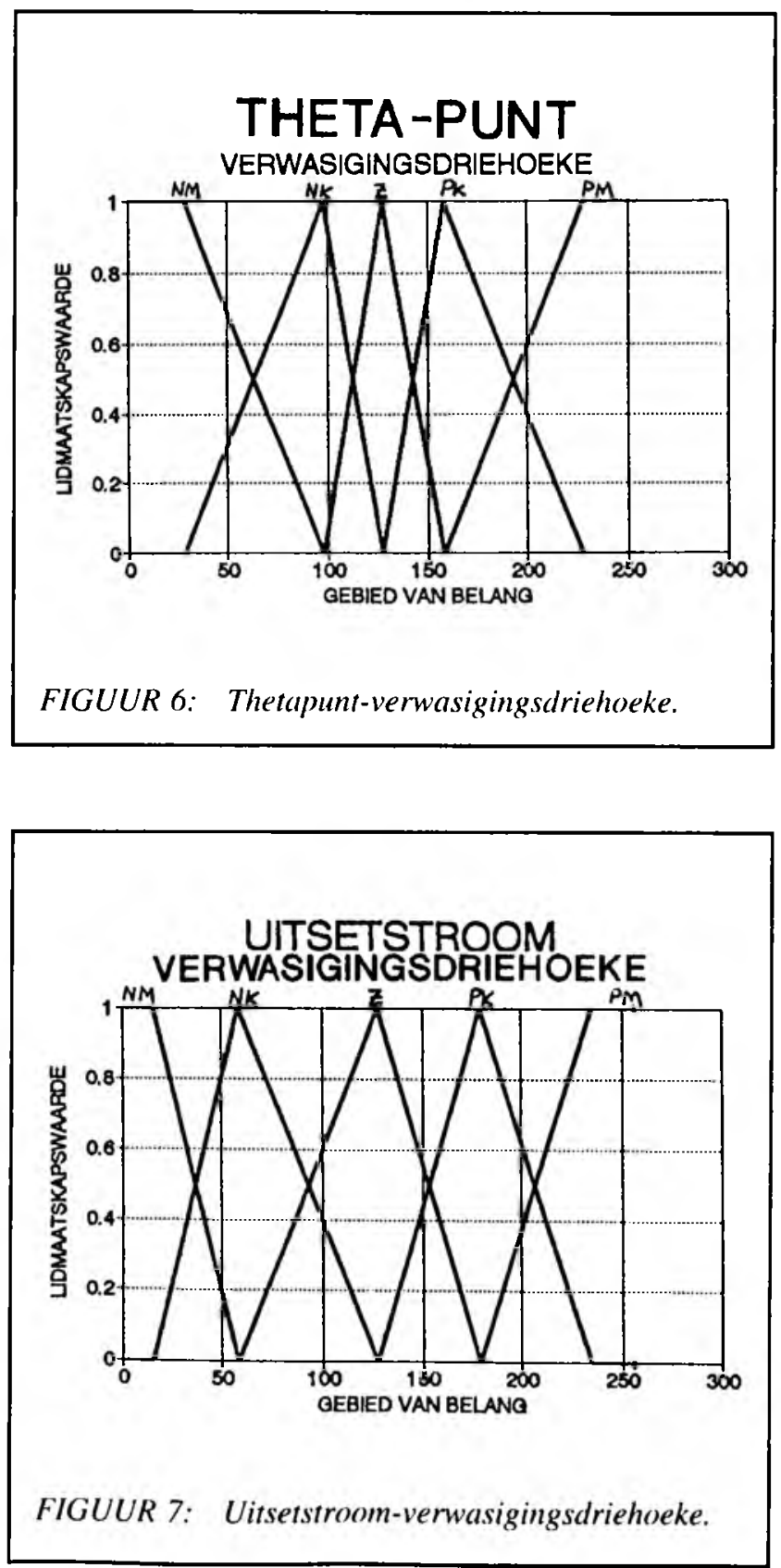


\section{TABEL 2 Uitgebreide wasige relasiematriks}

$\theta$

\begin{tabular}{|c|c|c|c|c|c|}
\hline & NM & NK & $Z$ & PK & PM \\
\hline$N M$ & & & NM & & \\
\hline$N K$ & NM & NK & NK & & \\
\hline$Z$ & NM & NK & $Z$ & PK & PM \\
\hline PK & & & PK & PK & PM \\
\hline PM & & & PM & & \\
\hline
\end{tabular}

pendulum te verhoog.

Die lidmaatskapfunksie van die stroom is ook verander. Die stelsel se uitsetstroom is effens verhoog vir klein uitsette, en is effens verlaag vir groot uitsette. Dit was nodig omdat die karretjie se traagheid beduidend was vir die versnelling. Deur die stroomdriehoeke aan te wend soos vermeld, is verseker dat die karretjie net genoeg reageer vir klein hoekuitwykings en hoeksnelhede; terwyl daar gesorg is dat dit nie oorreageer vir groter hoekuitwykings nie. Die stroomdriehoeke was ook effens onsimmetries weens die onsimmetriese respons van die gelykstroommotor.

Die lidmaatskapfunksie van die karretjie se posisie is gekies om maksimum te wees by die gestelde limiete van die bedryfsarea. Hierdie driehoeke en die verwasiging van die karposisie was nodig, aangesien twee reëls by die oorspronklike stel van reëls gevoeg is, in 'n poging om die karretjie in die middel van die bedryfsarea te hou tydens balansering van die pendulum.

Figure 5, 6 en 7 illustreer die gewysigde lidmaatskapfunksies. Die reëlmatriks wat oorspronklik voorgestel

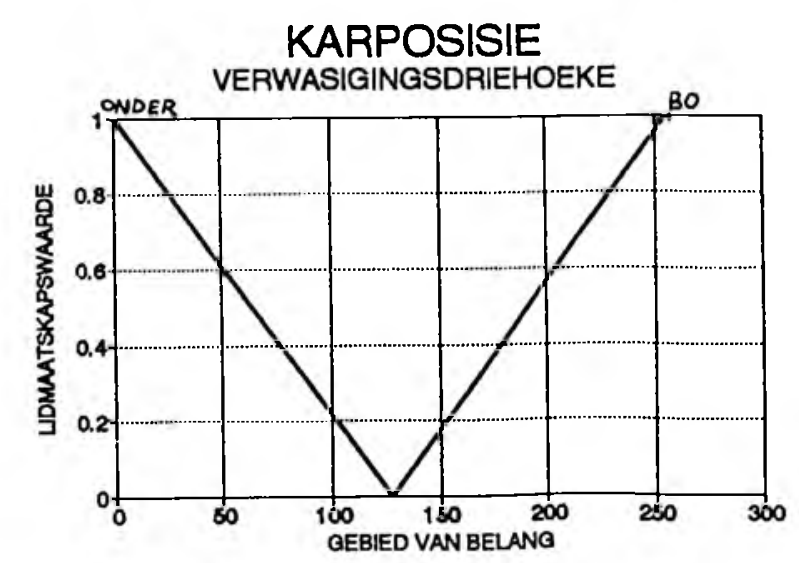

FIGUUR 8: Karposisie-verwasigingsdriehoeke. is, is uitgebrei na die van tabel 2 wat bevredigende resultate gelewer het. Posisiebeheer van die karretjie was egter nog 'n probleem. Die karretjie het, sodra die pendulum in een rigting kantel, geneig om in daardie rigting voort te beweeg en het glad nie na die middelpunt van die loopoppervlak probeer terugkeer nie. Hierdie probleem het hom veral voorgedoen by klein hoekuitwykings van die pendulum. Ten einde die probleem die hoof te bied, is daar twee addisionele reëls in die beheerder geimplementeer. Hierdie reĕls het die hoekposisie van die pendulum en die posisie van die karretjie in berekening geneem. Die twee reëls wat opgestel is, was die volgende:

Indien $\theta=P K$ en $x=$ "naby aan die bo-grens" dan moet $I=P G$ wees.

Indien $\theta=N K$ en $x=$ "naby aan die onder-grens" dan moet $I=N G$ wees.

Figuur 8 wys die karposisielidmaatskapfunksie.

Hierdie addisionele reëls het die stelselgedrag as volg beinvloed: neem aan dat die pendulum na regs gekantel het, en die karretjie besig is om na regs te beweeg ten einde die pendulum te balanseer. Sou die karretjie nou naby aan die grens kom, word die uitsetstroom sodanig verhoog dat die karretjie verby die pendulum versnel, sodat dit nou na links kantel. Die karretjie beweeg nou weer na die middel van die oppervlak. Dieselfde prosedure word gevolg as die linkergrens bereik word. Die byvoeging van die twee reëls het die gedrag van die stelsel baie voordelig beïnvloed. Die stelsel het nou geneig om in die middel van die loopoppervlak te bly. Die totale getal reëls wat gebruik is, was dus vyftien.

\section{MODERNE ONTWERPHULPMIDDELS}

Die bobeskrewe eksperimentele stelsel se wasige algoritme is deur konvensionele saamsteltaalprogrammering ontwikkel. Dit beteken dat aan die een kant elke verandering 
gedurende die ontwikkelingsproses lastige en tydrowende stappe (redigering, saamstelling, ens.) genoodsaak het, en aan die ander kant was dit baie moeilik om die nodige veranderinge vanuit die stelselgedrag te bepaal. In die algemeen bestaan wasige beheerders óf in die vorm van programmatuur in persoonlike rekenaars, voorsien met geskikte beheervoegvlakke, óf apparatuur (soos byvoorbeeld programmeerbare logiese beheerders voorsien met 'n spesiale wasige beheermodule) wat spesiale geïntegreerde vlokkies bevat ${ }^{30}$ en waarna wasige beheerprogrammatuur atgelaai kan word. Die instemmingsprosedure verg 'n metode om terugvoer ten opsigte van die wasige beheerder se kwaliteit te verkry. Om hierdie rede word spesiale programontwikkelingstelsels bemark, soos byvoorbeeld ${ }^{31}$ die opstel van wasige reëls en lidmaatskapfunksies in 'n grafiese manier kan manipuleer en dus die sikliese veranderings wat die instemmingsprosedure vereis, baie kan versnel. Buitendien word die effekte van enige verandering direk op die beheerkwaliteit raakgesien.

\section{GEVOLGTREKKING}

Die eksperimentele beheerder wat opgebou is, het in sy hoofdoel, die stabilisering van die omgekeerde pendulum, tot ' $n$ baie groot mate geslaag. Buitendien is die verband tussen die wasige reëlstruktuur, die lidmatskapfunksies en die aanleg onder beheer bestudeer om die ontwerpprosedure en sy beperkings te kan ontleed. Om al die meganiese eienskappe in ag te neem en vir hul ongunstige aksies te kompenseer, sou egter meer reěls nodig gewees het. Die

\section{LYS VAN TERME}

\begin{tabular}{|l|l|}
\hline Afrikaans & Engels \\
\hline wasig & fuzzy \\
wasige versameling & fuzzy set \\
wasige logika & fuzzy logic \\
reëlgebaseerdebeheerder & rule-based controller \\
selflerende beheerder & self-learning controller \\
relasionele wasige model & relational fuzzy model \\
wasige afbeelding & fuzzymapping \\
gebied van belang & universe of discourse \\
lidmaatskapwaarde & membership value \\
lidmaatskapfunksie & membership function \\
lidmaatskapvektor & membership vector \\
geordendepaar & ordered pair \\
linguisties & linguistic \\
steunsel & support \\
oorstappunt & crossover point \\
wasige enkeltjie & fuzzy singleton \\
snyding & intersection \\
vereniging & union \\
kompiementering & complement \\
wasigebeheerder & fuzzy controller \\
wasigedeelversameling & fuzzy subset \\
wasige relasie & fuzzy relation \\
wasigesaamsteioperator & fuzy compositional operator \\
verwasiging & fuzzification \\
ontwasiging & defuzzification \\
wasige reëlstruktuur & fuzzy rule structure \\
kundigheidsbasis & knowledgebase \\
& \\
\hline
\end{tabular}

toevoeging van nog reëls sou egter tot 'n langer verwerkingstyd gelei het. Aangesien die huidige mikrobeheerder nie baie vinnig is nie, kon die probleem met behulp van 'n vinniger mikrobeheerder ook opgelos word. Die mikrobeheerder moet verkieslik in staat wees om bewerkings met reële getalle vinnig te kan uitvoer. Daar is gevind dat die grootste gedeelte van die verwerkingstyd van die beheeralgoritme opgeneem is deur die vermenigvuldigings- en verdelingsoperasies wat met reële getalle gedoen is.

\section{SUMMARY}

Industrial controllers are required to accommodate complex non-linear plants and processes, variations in plant and environment, and be relatively insensitive to minor faults and disturbances. Central to the traditional theory of control is the construction of mathematical models which aim to describe the input - output relationship of the plant or process in terms of physical laws couched in mathematical terminology. Such models are idealised descriptions of reality and they are being kept simple and manageable by the assumptions of linearity and time invariance. As expected, such simplifications may result in a certain amount of information being ignored and this loss of information must be rectified later on by the tuning and adjustment of the controller in real plant operation. If done in a sufficiently thorough and careful way, this approach certainly works in many applications. However, when process complexity approaches or exceeds a certain threshold, even after simplifying assumptions, mathematical models not only become far too complex and intractable, but their accuracy and reliability in approaching the physical reality they attempt to model also become highly questionable. Traditional process modelling techniques, lacking a suitable methodology to take in to consideration uncertainties and incompleteness in process knowledge or complexity, simply ignored them, hence a significant amount of information, representing the gap between idealised and real-life control, was lost.

Traditionally, mathematical techniques inherently embodied exact solutions and until the early sixties, research in control theory tended to ignore uncertainty and imprecision. It became evident that excessive concern with precision has had an adverse effect on control theory, because it tended to focus only on problems susceptible to exact solutions. Practising engineers came to the conclusion a long time ago, that because of the many simplifications made in mathematical modelling, it is fallacious to thrive for more and more modelling accuracy. In 1973, Professor Zadeh of the University of California, Berkeley came to the following conclusion: "As the complexity of a system increases, our ability to make precise and yet significant statements about it diminishes until a threshold is reached beyond which precision and relevance become almost mutually exclusive characteristics." Thus the assumption that all engineering system modelling can be reduced to an exact set of algebraic of differential equations has been challenged by the fact that measurements, process modelling and control can never be exact for real-life complex 
processes.

Yet complex nonlinear processes and even those with partially unknown dynamics are successfully controlled by skilled human operators, using only experiential knowledge. The human control operator may not know why certain control actions produce good results, but at least he knows what to do and is able to satisfy complex performance criteria. Rather than mathematically model the process being controlled, the operator carries out his control actions in an experiential manner: he derives adaptive experiential linguistic (i.e. verbal rather than numerical) or qualitative models of the process, and generates qualitative control strategies (i.e. actions and responses) for given situations. Human control operators therefore make a unique contribution to the control of complex nonlinear and partially unknown processes, one which is not contained in traditional mathematical model-based approaches.

It would seem to be desirable to emulate the human operators' patterns by representing and computing qualitatively and imprecisely described processes in a systematic and logical manner, especially whenever a high level of precision is neither obtainable nor desirable. The advent of fuzzy logic was, in fact, precipitated by the need for a method, capable of processing imprecise, vague, uncertain, ill-defined quantities in a systematic and rigorous manner. Instead of a mathematical model, fuzzy logic-based industrial controllers can be invested with the experience of a trained human operator, yet, according to the reports, control performance can be just as good, often even better and always more consistent. The inherent advantage of fuzzy logic is that it represents a practical and nonmathematical alternative to controller design.

Fuzzy logic, introduced by Zadeh in 1965, uses imprecise, approximate, qualitative, common sense, linguistic (i.e. verbal rather than numeric) reasoning for uncertain and complex processes. Fuzzy logic deals with approximate reasoning in which truth is a matter of degree. Fuzzy logic may contain many imprecise linguistic (i.e. verbal) quantifiers such as, for example, “almost”, "sometimes", "a little", represented by any chosen number in the numeric interval $[0,1]$.

In conventional control methodology, what is modelled is the plant being controlled. In this modelling procedure (i.e. systems identification), the plant, assumed to be linear or nearly so, is characterised by a set of differential equations whose solution tells the controller how its parameters should be adjusted for each type of system behaviour required.

In control systems not amenable to automatic control, human operators are still being used and fuzzy control methodology focuses on such an operator's behaviour, i.e. how he would adjust the control parameters for a given set of circumstances. In fuzzy methodology, it is the human operator whose model is being identified while he is controlling the system! The fuzzy controller, based on the thus identified human operator model, becomes a logical model of the thinking process a human operator might go through when manipulating the system. This shift in focus from plant to person changes the entire approach to automatic control problems!

A rule-based fuzzy controller may occur in software or in hardware. At this point software realisations predominate, although it is expected that the use of dedicated fuzzy processor chips will increase sharply, especially in embedded applications where the performance of conventional controllers is enhanced by some added intelligence. In software and digital hardware realisations, the fuzzy controller program that runs in a personal computer, is embedded between an analog-to-digital and a digital-to-analog converter.

Fuzzy controllers used in industry today are invariably rule-based. Establishing a good rule base and an accompanying set of membership functions is not a trivial task in as much as it depends on the knowledge and insight of the design engineer into the plant or process dynamics being controlled. Fortunately, new graphics-based fuzzy controller software development tools run on a personal computer are now available which provide feedback to the designer regarding the sensitivity of the simulated plant to rule and membership functions changes made during an off-line tuning procedure. The cyclic tuning procedure, whereby changes in control performance can be directly observed from the graphics display of plant behaviour as a result of design changes in rules and membership functions, compensates for the designer's relative ignorance of the plant. Such tools can also produce high-speed fuzzy control whereby the entire rule set can be scanned and executed within a few milliseconds. This procedure results in a viable fuzzy control algorithm which can either be transcribed into a programmable logic controller (PLC), or downloaded into a microcontroller. Further refinements of the fuzzy control algorithm can be achieved by means of on-line tuning, whereby the actual plant is connected to the fuzzy controller by means of a hardware link. In short, thanks to modern and relatively inexpensive software design tools, a fuzzy controller can now, in fact, be adequately tested on a simulated as well as on a real plant.

\section{DANKBETUIGING}

Die outeur wil mnr. R.W. Pretorius graag bedank wat die pendulum en die wasige beheerder ontwerp en opgebou het.

\section{LITERATUURVERWYSINGS}

1. Zadeh, L. (1973). Outline of a new approach to the analysis of comlex systems and decision processes,IEEE Trans.Syst., Man, Cybern.SMC3,1, 28-44.

2. Shaw, I.S. (1993), Fuzzy model of a human control operator in a compensatory tracking loop,Int. J. Man-Machine Studies, 38, 305-332.

3. Krüger, J.J.\& Alberts, H.A. (1993). Fuzzy human-machine collaborative control of a nonlinear plant, Proceeding of the IFAC World Congress, Sydney, 8, 337.

4. Kosko, B. (1992). Neutral networks and fuzzy systems: a dynamical systems approach to machine intelligence. (Prentice-Hall International EnglewoodCliffs, N.J. USA.)

5. Pedrycz, W.S. (1983). An identification algorithm for fuzzy relational systems, Fuzzy Sets and Systems, 13.

6. Shaw, I.S. \& Krüger, J.J. (1989). New approach to fuzzy learning in dynamic systems, Electronic Letters, 25,12,796-797.

7. Xu, C.W. \& Lu, Y.Z. (1987). Fuzzy model identification and selflearning for dynamic systems, IEEE Trans. Sys., Man, Cybern. SMC17,4,683-689.

8. Shaw. I.S. \& Krüger, J.J. ( 1992). New fuzzy learning model with recursive estimation for dynamic systems, Fuzzy Sets and Systems, $48,2,217-229$. 
9. Yasunobu, S. \& Miyamoto, S. (1985). Automatic train operation by predictive fuzzy control. In Industrial applications of fuzzy control. Sugeno. M. ed. (Amsterdam, North Holland), 1-15.

10. Ollero, A., Boverie, S. \& Titli, A. (1994) Fuzzy control methodology and applications to automotive systems and mobile robots, Proceedings of the 2nd IFAC Conference on Intelligent Instrumentation and Control.

11. Hofbauer, P.. Arend. H.O.\& Pfannstiel, D. (1993). New heating system control based on the use of fuzzy logic, Proceedings of the First

European Congress on Fuzzy and Intelligent Technologies, 3, 10361042

12. OMRON Fuzzy Temperature Controller E5AF data sheets.

13. Shaw, I.S. (1992). Introducing fuzzy logic, Computech, 8,3.

14. Ortmeyer, T.H., Ahmed-Zaid, S., Mukundan, R.\& Boutwell, D. (1993) A fuzzy velocity controller for DC drives, Proc. First Eur. Congr. on Fuzzy and Int. Tech

15. Vrey, C.C.A., Shaw, I.S. \& Van Wyk, J.D. (1994) A new approach to control nonstandard induction machines using a fuzzy control algorithm Proceedigns of the 20th IEEE Annual conference on Industrial Electronics (IECON '94).

16. $\mathrm{Xu}, \mathrm{C} . \mathrm{W}$. ( 1989) Fuzzy systems identification, IEE Proceedings, 136 , D, 4, 146-150.

17. Maeda, M., Maeda, Y.\& Murakami, S. (1991). Fuzzy drive control of an autonomous mobile robot, Fuzzy Sets and Systems, 39, 195-204.

18. Aoki, S. \& Kawachi, S. (1990). Application of fuzzy control logic for deadtime processes in a glass melting furnace, Fuzzy Sets and Systems, $38,251-265$.

19. Neirac, F. \& Pescheux, B. (1992). Fuzzy logic and thermal systems management, Proceedings of the 2nd International Forum on Expert Systems and Computer Simulation in Energy Engineering, 3-2-1 to 3-
2-6

20. Umbers, l.G. \& King, P.J. (1980). An analysis of human decisionmaking in cement kiln control and the implications for automation, I $m$ t. J. ManMach. Studies. 12, 1, 11-23.

21. Yu, C., Zhiqiang (1990). Application of fuzzy reasoning to the control of an activated sludge plant, Fuzzy Sets and Systems, 38, 1-14.

22. Roffel, B., \& Chan, P.A. (1991). Fuzzy control of a polymerization reactor, Hydrocarbon Processing, 47-49.

23. Skowronski, W.M. \& Shaw, I.S. (1993). The application of fuzzy logic in traffic control,Proceedings of the First European Congress on Fuzzy and Intelligent Technologies, 3.

24. Krause, B.. Von Altrock, C., Limper, K.\& Schäfers, W. (1993). Development of a fuzzy knowledge-based system for the control of a refuse incinerator plant, Proceedings of the First European Congress on Fuzzy and Imelligent Technologies, 3, 1144-1150.

25. Yasunobu, S. \& Hasegawa, T. (1987). Predictive fuzzy control and its application for automatic container crane operation system, Proc. 2nd IFSA Congress, 349-352.

26. Proczyk, T.J \& Mamdani, E.H. (1979). A linguistic self-organizing process controller, Automatica, 15,15-30

27. Larsen, P.M. (1980). Industrial applications of fuzzy control,Int. J. ManMach. Sudies, 12, 1, 3-10.

28. Lee, C.C. ( 1990 ) Fuzzy logic in control systems: fuzzy logic controller Part I, IEEE Trans.Sys. Man., Cybern. SMC-20, 2,404-418.

29. Elgerd, O.I. (1967). Control systems theory (McGraw Hill Kogakusha Ltd).

30. Togai, M. \& Watanabe, H. (1986). Expert system on a chip: an engine for approximate reasoning, IEEE Expert, Fall 1986, 55-62.

31. Inform Sof tware Corp, infoTECHdata sheets, Aachen, Germany, 1993. 